\title{
Design Oxygen Saturation Monitoring in Telemedicine Smartphone System (TmSS)
}

\author{
I. Dewa Gede Hari Wisana \\ Medical Electronics Engineering \\ Department of Politeknik Kesehatan \\ Kementerian Kesehatan Surabaya \\ Pucang jajar Timur No.10 \\ Surabaya-East Java-Indonesia
}

\author{
Priyambada Cahya Nugraha \\ Medical Electronics Engineering \\ Department of Politeknik Kesehatan \\ Kementerian Kesehatan Surabaya \\ Pucang jajar Timur No.10 \\ Surabaya-East Java-Indonesia
}

\author{
Dwiana Estiwidani \\ Midwifery Department of Politeknik \\ Kesehatan Kementerian Kesehatan \\ Yogyakarta \\ JI. Mangkuyudan MJ III/304 \\ Yogyakarta-Central Java-Indonesia
}

\begin{abstract}
Oxygen Saturation alludes to the measure of oxygen that is in your circulatory system. The body requires a particular measure of oxygen in your blood to work appropriately. The typical scope of oxygen immersion for grown-ups is 94 to 99 percent. The reason for this examination is to plan oxygen Saturation with the Android interface. This gadget permits the Patient's to get a particular measure of oxygen in the blood. This gadget utilized a utilizations a fingertip sensor to recognize oxygen Saturation in the blood. The microcontroller utilizes an Arduino chip combining with AT-Mega328P. Bluetooth HC-05 used to send Oxygen Saturation information to Android, MIT application creator utilized for the android program. In view of the consequences of testing and estimation at that point contrast and another gadget, the after effects of the average were $2.22 \%$.
\end{abstract}

\section{Keywords}

Oxygen saturation, Bluetooth, Telemedicine

\section{INTRODUCTION}

Investigate identified with telemedicine need been broadly uncovered over past studies, yet the utilization of smartphonebased telemedicine Toward giving work to data straightforwardly to therapeutic staff in the event from claiming beyond the field of play parameters need not been broadly rehearsed. The true commitment for this Look into may be the generation of mechanical transformation innovations identified with telemedicine that camwood make connected and reveled in Toward the greater part individuals In a competitive price, On account the sum parts need aid effectively accessible in the nearby advertise. This Look into extensions those necessities of the down home wellbeing help supplies industry which is at present little Previously.

In light of past study, it might have been found that On 2015 Sang-Soo oak What's more Praveen Aroul outline oxygen immersion Furthermore pulse following utilizing AFE4403 [9]. This investigate clarifies how will get great caliber PPG signs. This PPG sign is used to get the $\mathrm{SpO} 2$ quality Also Additionally those heart rate esteem. However, this ponder doesn't underscore the computation of the $\mathrm{SpO} 2$ esteem alternately the heart rate value, thereabouts that the presentation best shows PPG signs. Following in the same year, Heu Also Liu also configuration An remote medicinal observing framework [10] which depicts the advancement of remote systems for sending majority of the data the middle of biometric sensors Also screening centres to increment allowed space around patients Toward following the heartbeats. The framework employments ZigBee engineering. However, those framework main saves information on control information main. Then, Fensli On 2016 outlines those clinical assessment of a remote ecg sensor [11] which makes a arrhythmia framework with remote electrocardiogram monitoring, particularly outlined for those finding of arrhythmias. This framework will screen patients ceaselessly will screen patients with arrhythmias with estimation comes about that might be straightforwardly seen on the character about fluid precious stone showcase (LCD). However, this framework doesn't yet utilization An telemedicine framework..

\section{MATERIAL AND METHOD}

\subsection{Experimental Setup}

Experimental Setup

This study uses male and female as a subjects aged 17-40 years. Sampling is randomly by taking data 5 times with a total of 10 samples.

1) Materials and Apparatus

This study uses a fingertip which will be placed on the patient's finger to detect the oxygen saturation. Using ATMega328 as a microcontroller, and Bluetooth to send data to android.

2) Experiment

In this study the researchers measured subject's Oxygen saturation who were randomly selected and compared the results of Oxygen Saturation with standard.

\subsection{Diagram Block}

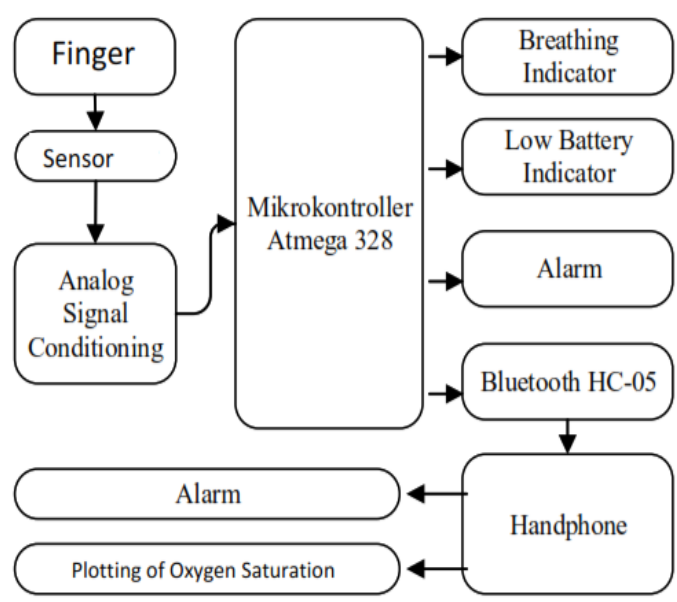

Fig 1. Diagram Block of Oxygen Saturation

In this research, Fingertip sensors were utilized to distinguish the Oxygen Saturation of the patient during breathing as found in Figure 1. The yield sensor that is still as opposition 
will enter the simple sign molding circuit so it very well may be prepared by the microcontroller. While the Oxygen saturation distinguished, the microcontroller will send information for Oxygen Saturation esteem counters to android by means of Bluetooth. At the point when Oxygen Saturation beneath the ordinary reach, the module will actuate the caution on the gadget and furthermore on android. On the Android show there is likewise a patient's Oxygen Saturation esteem.

\subsection{Analog Circuit}

The A large portion paramount and only those configuration will be the simple indicator molding circuit, Similarly as indicated for figure 2 which will be a voltage divider circuit, those distinction enhancer circlet and channel to figure 3 . This out serves will procedure simple signs thereabouts that those yield may be prepared on make transformed Toward a microcontroller.

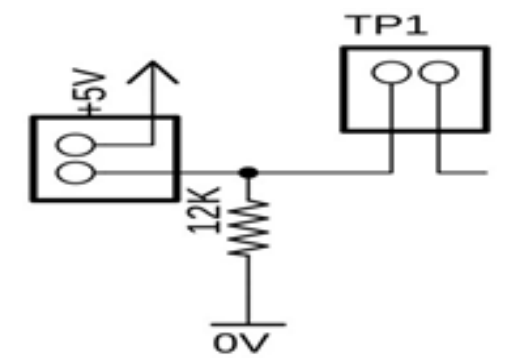

Fig 2. Voltage Devider

The circuit shown in Figure 2 is a voltage divider circuit, where this circuit will experience a change in output voltage when the flex sensor changes the curve caused by the breathing process of the patient

\subsection{Difference Amplifier}

The difference amplifier circuit using LM358 as the OP-Amp, is a circuit that serves to amplify the output from voltage divider, so that the difference in voltage when the patient is Counting Oxygen Saturation be seen more clearly, difference amplifier also used to setting sensitivity from the sensor to detected Oxygen Saturation. Furthermore, there is a low pass filter with frequency cut off $1 \mathrm{~Hz}$. The function of low pass filter is to eliminate noise that does not originate from breathing

\section{RESULT}

In this study, a trial has been carried out on the tool module by measuring Oxygen Saturation in patients directly and taking measurements to determine the accuracy of the module

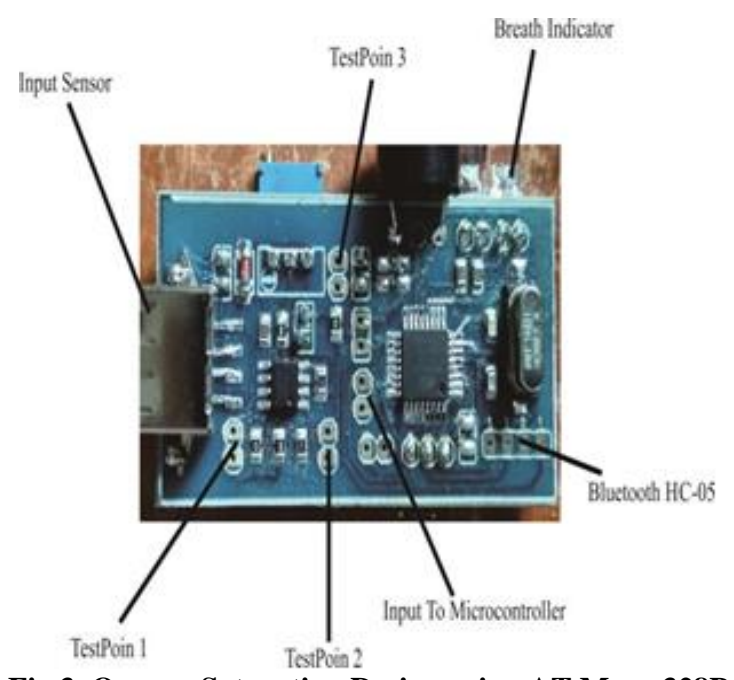

Fig 3. Oxygen Saturation Design using AT Mega 328P

Those simple sign molding out and microcontroller for oxygen immersion screen would demonstrated for figure 3 . This configuration comprises of a arrangement about voltage dividers, a Contrast enhancer circuit, Also an LPF channel. Those Contrast enhancer circlet employments the LM358. Ic which need two op-amp. In the voltage conveyance out there is multi-turn (50k) which serves will conform the affectability of the flex sensor readings. For the microcontroller this device around utilization ATMega328 as An control What's more utilization the Bluetooth HC-05 module Likewise those sender about information through those microcontroller.

\subsection{The Listing Program for ATMega328 Apnea Monitor}

In this study, the software was divided into two parts, namely for ATMega328 and for MIT APP Inventor. For the ATMega328 listing program shown in the Program Listing. It contains a sensor reading program and sending data to android via Bluetooth HC-05.

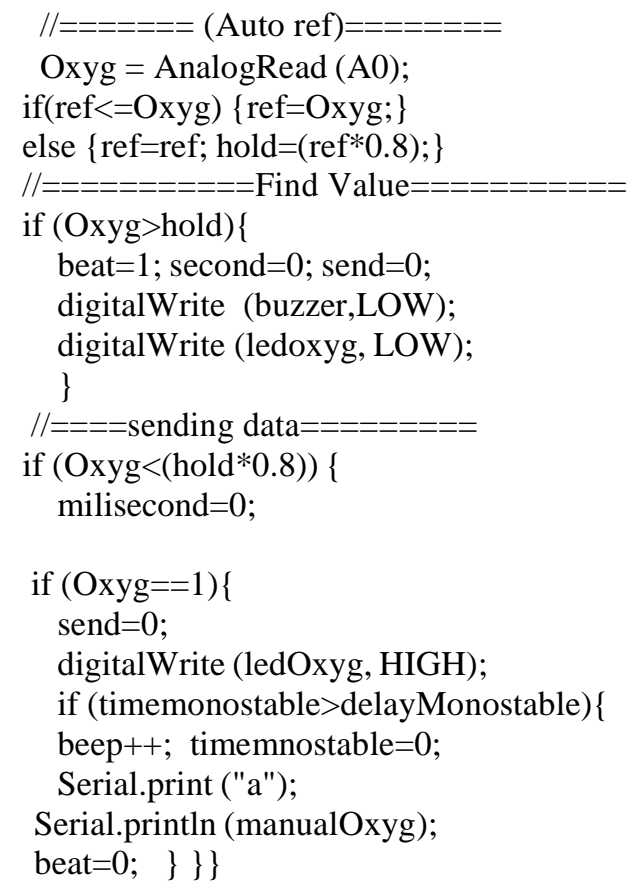

$/ /======$ Send Oxyg after 1 minutes========= if (milisecond $3>60003)\{$ 
Oxygsecondt=manualOxyg;

Serial.print ("b");Serial.println(Oxygsecond); manualOxyg=0;

milisecond $=0 ;\}$

$/ /======$ Detect Oxyg $============$
if $($ second $>10000)\{$ if $($ send $==0)\{$

Serial.print("c");Serial.println(1); digitalWrite

(buzzer,HIGH); send=1;\}\}

if(Oxyg >hold $)\{$

if (milisecond $>10000)\{$ if

(send==0)\{

Serial.print("c");Serial.pr

intln(1); digitalWrite

(buzzer,HIGH);

send $=1 ;\}\}$

\subsection{Timer}

The timer is used to calculate the time of stopping the Oxygen Saturation, and when the Oxygen saturation stops more than 10 seconds the tool will give a warning by activating the alarm.

Table 1. The difference between Timer and Standart

\begin{tabular}{ccc}
\hline Design & Standard & Difference \\
\hline 10 & 10.22 & 0.22 \\
10 & 10.20 & 0.20 \\
10 & 10.08 & 0.08
\end{tabular}

Table 2. Measurement Voltage in Left side and right side of the sensor

\begin{tabular}{ccc}
\hline No & Right Side & Left Side \\
\hline 1 & 2.56 & 2.16 \\
2 & 1.92 & 1.16 \\
3 & 2.4 & 2.24 \\
4 & 3.24 & 2.36 \\
5 & 2.88 & 1.64 \\
6 & 1.60 & 0.76 \\
7 & 1.80 & 1.44 \\
8 & 3.04 & 2.24 \\
9 & 3.60 & 2.88 \\
10 & 2.16 & 1.24 \\
Average & 2.52 & 1.812 \\
\hline
\end{tabular}

After testing the timer there are the difference between timer and standard. The biggest difference is 0.22 seconds and the smallest difference is 0.08

\subsection{Signal Oxygen Saturation}

Signal on Oxygen saturation Measure by Digital Osciloscope.

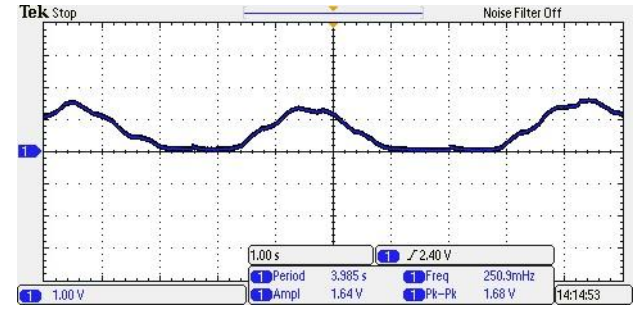

Fig4. Oxygen Saturation Signal before Amplified

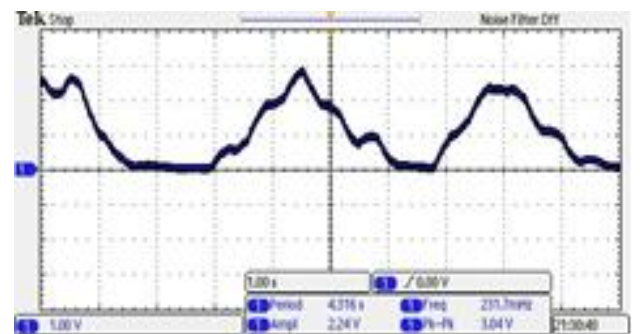

Fig.5 Oxygen Saturation After Amplified

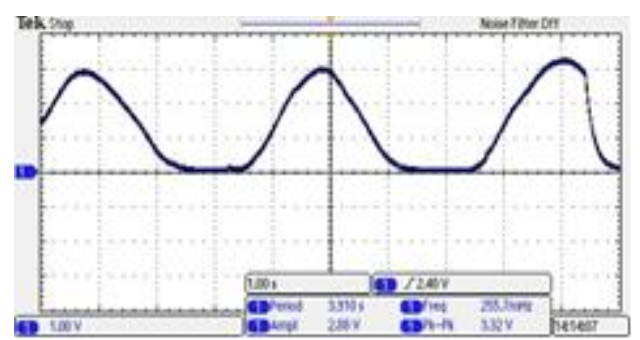

Fig.6 Oxygen Saturation After Amplified-Filtering

Table 3. Measurement Mean in the oxygen saturation

\begin{tabular}{cccccc}
\hline Resp. & Tool & Mean & & & \\
\hline 1 & Modul & 98.34 & 0.055 & 0.024 & 0.555 \\
\hline & $\begin{array}{c}\text { Patient } \\
\text { Monitor }\end{array}$ & 98.32 & 0.084 & 0.037 & - \\
\hline 2 & Modul & 98.1 & 0.071 & 0.032 & 0.555 \\
\hline & $\begin{array}{c}\text { Patient } \\
\text { Monitor }\end{array}$ & 98.12 & 0.084 & 0.037 & - \\
\hline 3 & Modul & 98.44 & 0.114 & 0.051 & 2.220 \\
\hline & $\begin{array}{c}\text { Patient } \\
\text { Monitor }\end{array}$ & 98.36 & 0.089 & 0.040 & - \\
\hline 4 & Modul & 98.38 & 0.192 & 0.086 & 1.165 \\
\hline & $\begin{array}{c}\text { Patient } \\
\text { Monitor }\end{array}$ & 98.32 & 0.148 & 0.066 & - \\
\hline 5 & Modul & 98.06 & 0.055 & 0.024 & 0.555 \\
\hline & $\begin{array}{c}\text { Patient } \\
\text { Monitor }\end{array}$ & 98.08 & 0.045 & 0.020 & - \\
\hline
\end{tabular}

Based on the results of comparisons using a patient monitor obtained different results / the difference in value. The largest error value obtained is $2.22 \%$ and the smallest is $0.55 \%$. The uncertainty value is obtained because there are still external 
factors, such as the location of the sensor module with a comparison. So the uncertainty value must be calculated too.

\subsection{ROC Curve in TMSS Oxygen Saturation}

The ROC curve on the Oxygen saturation data sending TMSS was taken from Sensor data transmission at the distance of respondents aged 17-40 years old and then performed calculations to obtain the ROC curve as shown in Fig.7 with AUC is Sensitivity $92 \%$.

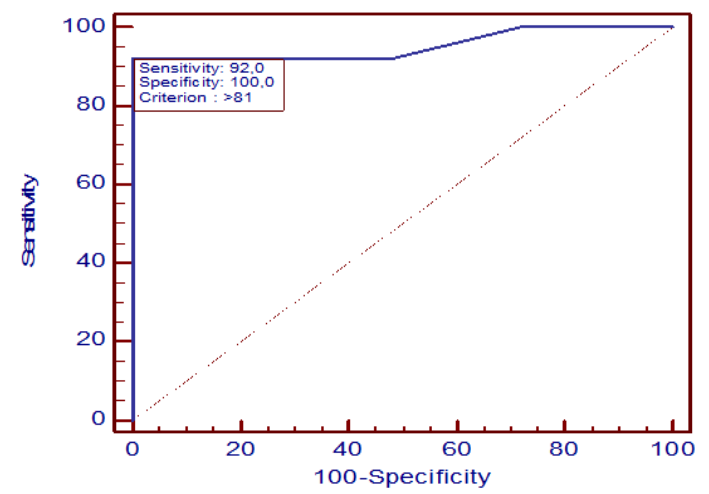

Fig 7 ROC Curve for Oxygen Saturation

\section{DISCUSSION}

The Oxygen Saturation design has been examined and tested completely in this study. Based on the result after measuring respiration signal from 10 subject, as seen above in the table can be conclude that the average of amplitude from the right side is 2.52 Volt and the average from the left side is 1.812 , so the right side is better to place the sensor.

Furthermore, based on the results after compared measurement using standard there are differences in the measurement results. The biggest error value is $2.20 \%$ and the smallest is $0.55 \%$. The uncertainty value is obtained because there are still other factors that influence the measurement results, such as the location of the finger tip sensor at the time of measurement, and respiration from the respondent is not always stable. So the value of uncertainty must also be calculated. The biggest value is 1.29 and the smallest value is 0.20 .

\section{CONCLUSION}

This Study Has Demonstrated The Development Of Finger tip Sensor To Monitoring TheOxygen Saturation of The Patient's. This Study Was Built Based On Bluetooth With Android Interface. After Testing The Design, There Are Needs To Improvement in filter

\section{REFERENCES}

[1] G. Vinci et al., "Six-Port Radar Sensor for Remote Respiration Rate and Heartbeat Vital-Sign Monitoring," IEEE Trans. Microw. Theory Tech., vol. 61, no. 5, pp. 2093-2100, 2013.

[2] J. A. Dawson and C. J. Morley, "Seminars in Fetal \& Neonatal Medicine Monitoring oxygen saturation and heart rate in the early neonatal period," Semin. Fetal Neonatal Med., pp. 1-5, 2010.

[3] E. M. J. Durlinger et al., "Hyperoxia: At what level of SpO 2 is a patient safe? A study in mechanically ventilated ICU patients," J. Crit. Care, vol. 39, no. November 2014, pp. 199-204, 2017.

[4] Z. Jia et al., "HB-Phone: a Bed-Mounted GeophoneBased Heartbeat Monitoring System," 978-1-5090-08025/16/\$31.00@2016 IEEE, 2016.

[5] A. A. K. Gupta, M. Pandey, "Micocontroller Based Cardiac Counter System," IJEAM, vol. 02, no. 01, 2013.

[6] W. M. Jubadi and A. H. B. Rate, "Heartbeat Monitoring Alert via SMS," IEEE Symp. Ind. Electron. Appl., no. Isiea, pp. 1-5, 2009.

[7] S. Kästle, F. Noller, S. Falk, A. Bukta, E. Mayer, and D. Miller, "A new family of sensors for pulse oximetry," Hewlett-Packard J., vol. 48, no. 1, pp. 39-61, 1997.

[8] A. Report, "How to Design Peripheral Oxygen Saturation ( SpO 2 ) and Optical Heart Rate Monitoring ( OHRM ) Systems Using the," Appl. Rep., no. March, pp. 1-7, 2015.

[9] Z. Q. He, W. Xu, and G. X. Liu, "Design of a wireless medical monitoring system," 2011 Int. Conf. Comput. Manag. CAMAN 2011, pp. 1-3, 2011.

[10] R. Fensli, T. Gundersen, T. Snaprud, and O. Hejlesen, "Clinical evaluation of a wireless ECG sensor system for arrhythmia diagnostic purposes," Med. Eng. Phys., vol. 35, no. 6, pp. 697-703, 2013.

[11] S. Misra and S. Chatterjee, Social choice considerations in cloud-assisted WBAN architecture for post-disaster healthcare: Data aggregation and channelization, vol. 284. 2014.

[12] M. Abo-Zahhad, S. M. Ahmed, and O. Elnahas, "A wireless emergency telemedicine system for patients monitoring and diagnosis," Int. J. Telemed. Appl., vol. 2014, 2014 